\title{
ASTRONOMIA AGRÍCOLA INFLUENCIA OS ASPECTOS PRODUTIVOS E FISIOLÓGICOS DA ALFACE?
}

\author{
Bruno do Nascimento Silva ${ }^{1}$; ${ }^{*}$ Hozano de Souza Lemos Neto ${ }^{2}$; Marcelo de Almeida \\ Guimarães $^{3}$; Pedro Rodrigues Magalhães ${ }^{4}$; Rosilene Oliveira Mesquita ${ }^{5}$ \\ ${ }^{1}$ Graduando do curso de Agronomia, na Universidade Federal do Ceará, Campus do \\ Pici, Fortaleza, Ceará \\ ${ }^{2}$ Pós-Graduando do Programa de Doutorado em Agronomia/Fitotecnia, na \\ Universidade Federal do Ceará, Campus do Pici, Fortaleza, Ceará (E-mail: \\ hozanoneto@hotmail.com) \\ ${ }^{3}$ e 5 Professores Doutores do Curso de Agronomia (Departamento de Fitotecnia) na \\ Universidade Federal do Ceará, Campus do Pici, Fortaleza, Ceará \\ ${ }^{4}$ Pós-Graduando do Programa de Mestrado em Fitotecnia, na Universidade Federal \\ do Ceará, Campus do Pici, Fortaleza, Ceará.
}

Recebido em: 03/10/2016 - Aprovado em: 21/11/2016 - Publicado em: 05/12/2016 DOI: 10.18677/EnciBio_2016B_009

Dentre as diferentes correntes do cultivo orgânico, existe a chamada agricultura biodinâmica, que baseia-se no calendário astronômico agrícola. De acordo com esse calendário, existem períodos que são favoráveis a produção dos diferentes órgãos da planta (raiz, folha, flor e fruto) e um período que é desfavorável as práticas agrícolas (perigeu). Diante do exposto, objetivou-se avaliar a influência da astronomia agrícola em aspectos produtivos e fisiológicos da alface. O delineamento experimental utilizado foi o de blocos ao acaso, com cinco repetições e seis tratamentos, sendo estes as datas de semeadura e de transplantio em diferentes dias de acordo com o calendário astronômico agrícola (dia de raiz, folha, flor, fruto, perigeu na semeadura e perigeu na semeadura e transplantio). Avaliaram-se altura e diâmetro da planta, número de folhas, massa de matéria fresca e seca de parte aérea, clorofila "a" e "b" e trocas gasosas. Foram observadas diferenças para altura da planta, fotossíntese, transpiração e eficiência instantânea de carboxilação. As plantas semeadas em dias de folha e de fruto foram as que apresentaram maiores médias de fotossíntese e eficiência de carboxilação. Já para a transpiração o dia de fruto foi o que teve as maiores médias. Pode-se concluir que há influência das diferentes datas de semeadura e transplantio na fisiologia (trocas gasosas) da alface.

PALAVRAS-CHAVE: biodinâmica, Lactuca sativa L.,; trocas gasosas. 


\title{
AGRICULTURAL ASTRONOMY INFLUENCE ON PRODUCTIVE AND PHYSIOLOGICAL ASPECTS OF LETTUCE?
}

\begin{abstract}
Among the different streams of organic farming, there is the so-called biodynamic agriculture, which is based on agricultural astronomical calendar. According to this calendar, there are periods that are favorable to the production of different plant organs (root, leaf, flower and fruit) and a period that is unfavorable for agricultural practices (perigee). Given the above, this study aimed to evaluate the influence of astronomy agricultural in production and physiological aspects of lettuce. The experimental design was randomized blocks, with five replications and six treatments, which are the dates of sowing and transplanting in different days according to the agricultural astronomical calendar (root, leaf, flower, fruit, perigee at sowing and perigee at sowing and transplanting days). Was evaluated height and diameter of the plant, number of leaves, fresh weight and shoot dry, chlorophyll "a" and "b" and gas exchanges. Differences in plant height, photosynthesis, transpiration and instantaneous carboxylation efficiency were observed. Plants sown in days of leaf and fruit showed the highest means of photosynthesis and carboxylation efficiency. As for sweating the day of fruit was the one with the highest average. It can be concluded that there is influence of the different dates of sowing and transplanting gas exchange lettuce.
\end{abstract}

KEYWORDS: Lactuca sativa L., biodynamic, gas exchange.

\section{INTRODUÇÃO}

A alface (Lactuca sativa L.) é a hortaliça folhosa com maior volume de produção no Brasil, sendo consumida na forma in natura em saladas e sanduiches (HEREDIA ZÁRATE et al., 2010). É uma planta de origem mediterrânea (Europa e Ásia Ocidental) (FILGUEIRA, 2008) e a sua introdução no Brasil foi feita pelos portugueses por volta do século XVI (SALA \& COSTA, 2012).

No ano de 2012, essa folhosa movimentou no varejo aproximadamente $R \$ 8$ milhões com uma produção anual de 1,6 milhões de toneladas, ficando atrás apenas do tomate e da melancia (ABCSEM, 2014). Esse grande volume de produção, aliado ao cultivo intensivo é um grande gerador de empregos no campo, o que torna uma cultura importante para o setor agrícola.

Ao longo do processo de modernização da agricultura no Brasil, muitos problemas vêm surgindo com relação não só a saúde humana, como também os impactos dos sistemas agrícolas sob o meio ambiente. $O$ uso excessivo de fertilizantes minerais e agrotóxicos contribui para que haja a contaminação dos solos, da água e dos alimentos (ALENCAR et al., 2013).

Em virtude disso, a agricultura orgânica surgiu para contrapor ao modelo clássico, que usa insumos que contaminam o solo, a água e prejudica toda a natureza. Esse modelo de agricultura opta pelo manejo ecológico, respeitando a relação planta, solo e ambiente por meio de práticas sustentáveis (PENTEADO, 2010). Além disso, a agricultura orgânica também tem vantagens sociais, pois normalmente requer mais mão de obra, aumentando as oportunidades de emprego e fixando o homem no campo (KHATOUNIAN, 2001; SOUZA \& RESENDE, 2006).

Dentro desse modelo de agricultura orgânica, existe a chamada agricultura biodinâmica. Essa corrente do movimento orgânico tem como base a antroposofia, que busca resgatar a sintonia do homem com a natureza, que foi perdida no decorrer dos anos. A agricultura biodinâmica é regida pelo calendário agrícola, em 
que as práticas agrícolas (semeio, poda, enxertia, transplantio) possuem períodos favoráveis ou desfavoráveis baseado na posição da lua e dos astros (THUN, 1986). De acordo com esse calendário, existem 4 datas que favorecem as diferentes partes da planta (raiz, folha, flor e fruto) e uma data em que qualquer prática agrícola é desaconselhável, conhecido como perigeu (THUN, 2015).

Essa forma de agricultura com o passar dos anos foi deixando de ser praticada pelas gerações jovens, sendo ainda praticada no meio rural por pequenos agricultores (NODARI, 2015). Diante do exposto, objetivou-se avaliar a influência da astronomia agrícola nos aspectos produtivos e fisiológicos da alface e se realmente existe um dia ideal para o plantio conforme dita o calendário astronômico agrícola.

\section{MATERIAL E MÉTODOS}

O experimento foi realizado na Horta Didática (3936 '6"S, 37\%48'36" W e 21,0 $m$ de altitude), sob manejo orgânico, em Fortaleza-CE no período de junho a agosto de 2015. Segundo a classificação climática de Koppen o clima é do tipo Aw', ou seja, tropical chuvoso. As médias de temperaturas mínimas e máximas no período foram de $30,3^{\circ} \mathrm{C}$ e $22,0^{\circ} \mathrm{C}$, umidade relativa do ar de $75 \%$ e precipitação de $28 \mathrm{~mm}$.

O solo da área de plantio apresentava classificação textural do tipo francoarenoso, onde antes do plantio, foram retiradas amostras do solo e encaminhadas para análise físico-química (Tabela 1).

TABELA 1- Análise físico-química do solo (S) e substratos para produção das mudas correspondente a cada tratamento na área de plantio. T1- dia de fruto, T2- dia de raiz, T3- dia de flor, T4- perigeu aos 25 DAS; T5- perigeu aos 28 DAS, T6- dia de folha.

\begin{tabular}{|c|c|c|c|c|c|c|c|c|}
\hline & \multirow[t]{2}{*}{$\mathrm{pH}$} & $\mathrm{P}$ & $\mathrm{K}$ & $\mathrm{Ca}$ & $\mathrm{Mg}$ & $\mathrm{H}+\mathrm{Al}$ & SB & CTC \\
\hline & & \multicolumn{2}{|c|}{$\mathrm{mg} \mathrm{dm}^{-3}$} & \multicolumn{5}{|c|}{$\mathrm{cmol}_{\mathrm{c}} \mathrm{dm}^{-3}$} \\
\hline Solo & 6,2 & 261,4 & 430 & 11,1 & 8,7 & 2,64 & 20,9 & 23,0 \\
\hline $\mathrm{T} 1$ & 6,3 & 261,4 & 81 & 9,8 & 3,9 & 1,65 & 13,91 & 15,5 \\
\hline $\mathrm{T} 2$ & 6,2 & 261,4 & 110 & 10,1 & 4,3 & 1,82 & 14,68 & 16,50 \\
\hline T3 & 6,2 & 261,4 & 121 & 8,8 & 3,9 & 1,49 & 13,01 & 14,50 \\
\hline T4 & 6,2 & 261,4 & 290 & 9,9 & 5,2 & 1,82 & 15,84 & 17,66 \\
\hline T5 & 6,4 & 261,4 & 290 & 9,7 & 4,6 & 1,65 & 15,04 & 16,69 \\
\hline \multirow[t]{3}{*}{ T6 } & 6,2 & 261,4 & 155 & 10,1 & 4,3 & 1,82 & 14,80 & 16,62 \\
\hline & CTC $(\mathrm{t})$ & $\mathrm{Al}$ & $\mathrm{V}$ & $\mathrm{M}$ & Areia & Silte & Argila & Text. \\
\hline & \multicolumn{3}{|c|}{$\mathrm{cmol}_{\mathrm{c}} \mathrm{dm}^{-3}$} & \multicolumn{4}{|c|}{$\%$} & \\
\hline Solo & 20,90 & 0,0 & 89 & 0,0 & 6 & 18 & 76 & Arenosa \\
\hline $\mathrm{T} 1$ & 13,91 & 0,0 & 89 & 0,0 & 6 & 12 & 82 & Arenosa \\
\hline $\mathrm{T} 2$ & 14,68 & 0,0 & 89 & 0,0 & 7 & 11 & 82 & Arenosa \\
\hline T3 & 13,01 & 0,0 & 90 & 0,0 & 9 & 8 & 84 & Arenosa \\
\hline T4 & 15,84 & 0,0 & 90 & 0,0 & 10 & 12 & 82 & Arenosa \\
\hline T5 & 15,04 & 0,0 & 90 & 0,0 & 6 & 10 & 82 & Arenosa \\
\hline T6 & 14,80 & 0,0 & 89 & 0,0 & 7 & 110 & 83 & Arenosa \\
\hline
\end{tabular}

Fonte: Laboratório de Análise Solos de Viçosa Ltda. 2015. pH - potencial hidrogênionico: $\mathrm{H}_{2} \mathrm{O}$ (1: 2,5), $\mathrm{P}$ - fósforo, $\mathrm{K}$ - potássio, $\mathrm{Ca}$ - cálcio, $\mathrm{Mg}$ - magnésio, $\mathrm{Al}$ - alumínio, $(\mathrm{H}+\mathrm{Al})$ - acidez potencial, SB -soma de bases, CTC - capacidade de troca de cátions. V- saturação por bases, m- saturação por alumínio, Text - textura. Extrator Mehlich.

experimento foi conduzido no delineamento em blocos ao acaso, com cinco repetições e seis tratamentos (dia de raiz, folha, flor, fruto, perigeu na 
semeadura e perigeu na semeadura e transplantio). A parcela tinha $1,5 \mathrm{~m}^{2}$, com 40 plantas, sendo consideradas como área útil as 2 fileiras centrais.

A semeadura foi realizada em cinco datas estabelecidas pelo Calendário Astronômico Agrícola 2015: dia 4 de junho correspondeu ao 'dia de fruto' (lua em sagitário); 6 de junho ao 'dia de raiz' (lua em capricórnio); 8 de junho ao 'dia de flor' (lua em aquário) 10 de junho ao 'perigeu' (período inadequado para práticas agrícolas); e 11 de junho ao 'dia de folha' (lua em peixes). Foram utilizadas sementes de alface da cultivar Lucy Brown, semeadas em bandejas de polipropileno de 200 células, preenchidas com composto orgânico (compostagem de esterco bovino e restos vegetais) produzido na Horta Didática e vermiculita na proporção de 9:1 (v/v).

As mudas ficaram protegidas em abrigo durante 28 dias, desse modo, a lua completou seu ciclo no zodíaco e tanto a semeadura quanto o transplantio favoreceram o mesmo órgão da planta. No entanto, o perigeu foi dividido em: a) transplante aos 25 dias, buscando coincidir o perigeu tanto na semeadura como no transplantio; b) 28 dias, obedecendo a data do perigeu na semeadura. Com o intuito de priorizar o transplantio, tanto a semeadura como o transplantio estiveram sob influência da lua descendente (THUN, 1986).

O transplantio foi realizado aos 28 Dias Após a Semeadura (DAS), com exceção de do perigeu, transplantado aos 25 DAS. Antes do transplantio das mudas foi realizada uma adubação orgânica com $10 \mathrm{~L} \mathrm{~m}^{-2}$ de composto orgânico, seguindo a análise de solo.

As mudas foram transplantadas quando apresentavam de quatro a seis folhas definitivas, sempre no período da manhã (07:00 h). O espaçamento utilizado foi $0,20 \times 0,20 \mathrm{~m}$ entre plantas e fileiras. $O$ transplantio das plantas correspondentes a cada um dos tratamentos foi realizado nas seguintes datas: dia de fruto (2 de julho); dia de raiz (4 de julho); perigeu 25 DAS (coincidindo a semeadura e o transplantio); dia de flor (6 de julho); perigeu 28 DAS (coincidindo somente a semeadura) e dia de folha ( 9 de julho).

A adubação de cobertura foi feita semanalmente, na quantidade aproximada de $1,5 \mathrm{~L} \mathrm{~m}^{-1}$ linear. Para a primeira adubação foi utilizada somente composto orgânico; para as adubações seguintes utilizou-se composto orgânico mais a cama de frango na proporção de 1:1 (v/v). Durante a condução foram realizadas capinas manuais, bem como a irrigação por microaspersão duas vezes ao dia, início da manhã e fim da tarde.

Aos 57 DAS foram feitas as avaliações de trocas gasosas e de pigmentos fotossintéticos. Para as avaliações de trocas gasosas, utilizou-se o analisador de gás infravermelho (IRGA) modelo LI-6400XT da marca Licor, onde mensurou-se a concentração interna de $\mathrm{CO}_{2}$ na câmara subestomática ( $\mathrm{Ci}$-ppm), condutância estomática (gs-mol, $\mathrm{m}^{-2} \mathrm{~s}^{-1}$ ), taxa fotossintética (A-umol, $\left.\mathrm{m}^{-2} \mathrm{~s}^{-1}\right)$, transpiração (mol, $\mathrm{m}^{-}$ ${ }^{2} \mathrm{~s}^{-1}$ ) razão entre a concentração de $\mathrm{CO}_{2}$ na câmara subestomática e a concentração de $\mathrm{CO}_{2}$ do ambiente $(\mathrm{Ci} / \mathrm{Ca})$ e a eficiência instantânea de carboxilação $(\mathrm{A} / \mathrm{Ci})$. Para os pigmentos fotossintéticos utilizou-se o medidor eletrônico (Clorofilômetro) SPAD da marca Falker modelo CFL 1030, onde avaliou-se as clorofilas 'a' e 'b'.

Após isso, as plantas foram colhidas para as avaliações quantitativas de: a) altura de planta (AP) - realizado do nível do solo até o ponto de inserção da última folha em crescimento; b) diâmetro da planta (DP) - medindo-se a maior distância entre as extremidades opostas da folha; c) número de folhas (NF) - quantidade de folhas totalmente expandidas; d) massa de matéria fresca da parte aérea (MFPA) massa da planta em balança, considerando caule e folhas; e) massa de matéria ENCICLOPÉDIA BIOSFERA, Centro Científico Conhecer - Goiânia, v.13 n.24; p. 115 
seca de parte aérea (MSPA) - as amostras foram submetidas a secagem em estufas com circulação forçada de ar a $70{ }^{\circ} \mathrm{C}$ durante 72 horas até a obtenção do peso constante, onde em seguida fez-se a pesagem em balança de precisão.

Os dados obtidos foram submetidos à análise de variância (teste F). Para comparação das médias utilizou-se o teste de Scott-Knott $(p<0,05)$.

\section{RESULTADOS E DISCUSSÃO}

Houve diferenças entre as datas de semeaduras apenas para a variável altura de planta (Tabela 2). Para diâmetro, número de folhas, massa de matéria fresca e seca de parte aérea e clorofilas não houve diferenças. Para AP, o dia de raiz foi o que proporcionou maiores médias, o que não era esperado, por se tratar de uma espécie folhosa, esperava-se que no dia de folha as plantas tivessem a maior altura. A semeadura nessa data pode ter sido favorecida pelo fenômeno de oposição que de acordo com THUN (2015), semeaduras quando feitas sob essa influência resultam em maior produtividade.

Fenômenos de oposição acontecem quando dois planetas, podendo o sol também fazer parte, se encontram separados a $180^{\circ}$ se visto da Terra. Como consequência, as forças se somam (THUN, 2015). Dessa forma, o efeito da lua muitas vezes é aumentado. Já as plantas de alface quando submetidas a semeadura e transplantio no perigeu (25 DAS) obtiveram a menor altura.

Esse resultado está de acordo com o calendário agrícola, pois o perigeu é a data imprópria para o cultivo, principalmente para semeadura, pois as forças que proporcionam o crescimento vegetal, são fracas. A vida vegetal é influenciada positivamente pela interação entre o sol e a Terra, porém a lua pode alterar essa harmonia. Desse modo, plantas semeadas no perigeu não conseguem ser puxadas para fora da Terra pelos impulsos solares (THUN, 2015), assim, a semeadura e o transplante no perigeu (25) foram os proporcionaram as menores alturas às plantas.

TABELA 2- Médias de altura e diâmetro da planta (AP e DP, cm), número de folhas (NF), massa de matéria fresca e seca total (MFT e MST, g) e clorofilas 'a' e 'b' (Clor 'a' e Clor 'b') de alface semeadas de acordo com o calendário de astronomia agrícola 2015.

\begin{tabular}{lccccccc}
\hline Tratamento & AP & DP & NF & MFT & MST & Clor a & Clor b \\
\hline Perigeu (25) & $9,70 \mathrm{c}$ & $28,42 \mathrm{a}$ & $19,10 \mathrm{a}$ & $166,92 \mathrm{a}$ & $6,87 \mathrm{a}$ & $21,73 \mathrm{a}$ & $4,42 \mathrm{a}$ \\
Perigeu (28) & $12,00 \mathrm{~b}$ & $28,23 \mathrm{a}$ & $19,40 \mathrm{a}$ & $178,80 \mathrm{a}$ & $7,08 \mathrm{a}$ & $21,24 \mathrm{a}$ & $4,19 \mathrm{a}$ \\
Raiz & $15,00 \mathrm{a}$ & $27,74 \mathrm{a}$ & $19,87 \mathrm{a}$ & $172,20 \mathrm{a}$ & $7,55 \mathrm{a}$ & $20,53 \mathrm{a}$ & $4,20 \mathrm{a}$ \\
Folha & $13,02 \mathrm{~b}$ & $30,16 \mathrm{a}$ & $21,17 \mathrm{a}$ & $164,60 \mathrm{a}$ & $7,72 \mathrm{a}$ & $20,74 \mathrm{a}$ & $4,12 \mathrm{a}$ \\
Flor & $11,94 \mathrm{~b}$ & $27,32 \mathrm{a}$ & $18,95 \mathrm{a}$ & $158,75 \mathrm{a}$ & $6,90 \mathrm{a}$ & $21,39 \mathrm{a}$ & $4,45 \mathrm{a}$ \\
Fruto & $12,77 \mathrm{~b}$ & $28,69 \mathrm{a}$ & $18,57 \mathrm{a}$ & $144,25 \mathrm{a}$ & $7,01 \mathrm{a}$ & $21,54 \mathrm{a}$ & $4,24 \mathrm{a}$ \\
- Mé-1ias & 12,40 & 28,43 & 19,53 & 164,25 & 7,19 & 21,19 & 4,27 \\
${ }^{1}$ CV (\%) & 11,47 & 7,88 & 8,88 & 25,54 & 18,82 & 5,14 & 6,89 \\
\hline
\end{tabular}

Médias seguidas por letras iguais, na coluna, não diferem entre si $(p>0,05)$, pelo teste Scott-Knott.

${ }^{1}$ Coeficiente de variação.

Não foi possível observar diferenças entre boa parte das variáveis encontradas na Tabela 2, talvez pelo fato das datas de semeaduras estarem muito próximas. Trabalhos feitos com alface por SOUZA (2003) mostraram diferenças no cultivo em diferentes fases lunares. Este autor avaliou o ritmo sideral da lua, diferente do presente estudo, que avaliou o ritmo sinódico da lua, que é a sua 
posição no zodíaco. Possivelmente esse resultado pode ter sido obtido por conta das influências cósmicas serem mais evidentes nas diferentes fases da lua (nova, crescente, cheia e minguante), do que apenas entre dias de plantio de acordo com a posição da lua no zodíaco.

Para as avaliações de trocas gasosas houve diferenças entre os tratamentos para a fotossíntese, transpiração e eficiência instantânea de carboxilação (Tabela 3). $O$ dia de fruto e o de folha foram os que possibilitaram as maiores médias de fotossíntese e eficiência de carboxilação. Para a transpiração o dia de fruto foi o que obteve a maior média. Já o dia de flor foi o que as plantas apresentaram as menores médias de fotossíntese e eficiências de carboxilação. Para as características de condutância estomática, concentração interna de $\mathrm{CO}_{2}$ e razão $\mathrm{Ci} / \mathrm{Ca}$ não foram observadas diferenças.

TABELA 3- Médias de fotossíntese $\left(A, \mu \mathrm{mol} \mathrm{m} \mathrm{m}^{-2} \mathrm{~s}^{-1}\right)$, condutância estomática (gs, mol $\left.\mathrm{m}^{-2} \mathrm{~s}^{-1}\right)$ concentração interna de $\mathrm{CO}_{2}(\mathrm{Ci}, \mathrm{ppm})$, transpiração $\left(E, \mathrm{~mol} \mathrm{~m}^{-2}\right.$ $\left.\mathrm{s}^{-1}\right)$, razão entre a concentração interna de $\mathrm{CO}_{2}$ e a externa ( $\left.\mathrm{Ci} / \mathrm{Ca}\right)$ e eficiência instantânea de carboxilação $(A / \mathrm{Ci})$ de alface semeadas de acordo com o calendário de astronomia agrícola 2015.

\begin{tabular}{lllllll}
\hline Tratamento & $A$ & Gs & $\mathrm{Ci}$ & $E$ & $\mathrm{Ci} / \mathrm{Ca}$ & $A / \mathrm{Ci}$ \\
\hline Perigeu (25) & $13,04 \mathrm{~b}$ & $0,36 \mathrm{a}$ & $317,83 \mathrm{a}$ & $0,005 \mathrm{~b}$ & $0,815 \mathrm{a}$ & $0,041 \mathrm{~b}$ \\
Perigeu (28) & $12,21 \mathrm{~b}$ & $0,35 \mathrm{a}$ & $318,54 \mathrm{a}$ & $0,005 \mathrm{~b}$ & $0,816 \mathrm{a}$ & $0,038 \mathrm{~b}$ \\
Dia de Raiz & $12,06 \mathrm{~b}$ & $0,37 \mathrm{a}$ & $322,99 \mathrm{a}$ & $0,005 \mathrm{~b}$ & $0,827 \mathrm{a}$ & $0,037 \mathrm{~b}$ \\
Dia de folha & $14,99 \mathrm{a}$ & $0,35 \mathrm{a}$ & $303,24 \mathrm{a}$ & $0,005 \mathrm{~b}$ & $0,780 \mathrm{a}$ & $0,049 \mathrm{a}$ \\
Dia de Flor & $10,50 \mathrm{c}$ & $0,38 \mathrm{a}$ & $332,29 \mathrm{a}$ & $0,006 \mathrm{~b}$ & $0,849 \mathrm{a}$ & $0,032 \mathrm{c}$ \\
Dia de fruto & $15,02 \mathrm{a}$ & $0,47 \mathrm{a}$ & $318,63 \mathrm{a}$ & $0,007 \mathrm{a}$ & $0,821 \mathrm{a}$ & $0,047 \mathrm{a}$ \\
- Médias & 12,97 & 0,38 & 318,92 & 0,006 & 0,818 & 0,041 \\
${ }^{1} \mathrm{CV}(\%)$ & 7,25 & 21,11 & 4,36 & 11,61 & 4,43 & 8,61 \\
\hline
\end{tabular}

Médias seguidas por letras iguais, na coluna, não diferem entre si ao nível de 5\% de significância, pelo teste Scott-Knott. ${ }^{1}$ Coeficiente de variação.

A carboxilação é a etapa inicial no ciclo de Calvin e essa por sua vez é importante, pois capta o dióxido de carbono atmosférico e esse poderá ser transformado em compostos orgânicos pela planta em presença de luz (TAIZ \& ZEIGER, 2013). Dessa forma, maiores eficiências de carboxilação podem representar maiores médias de fotossíntese, como foi observado para o dia de folha e dia de fruto.

Já no processo de transpiração, a abertura dos estômatos permite que o $\mathrm{CO}_{2}$ atmosférico possa ser captado. Como consequência desses fenômenos acontece a perda de água na forma de vapor (KERBAUY, 2012). Logo essa maior taxa de transpiração no dia de fruto justifica maiores valores de carboxilação e eficiência de carboxilação.

Possivelmente o fato de não ter havido diferenças entre a maioria das variáveis estudadas, está relacionado as proximidades nas datas de semeadura, uma vez que todos os tratamentos foram semeados dentro de sete dias. Esse período pode não ser suficiente para as forças cósmicas causar uma alteração de modo a interferir de maneira significativa na produção e nos pigmentos da planta de alface. 


\section{CONCLUSÃO}

Há influência da astronomia agrícola na fisiologia (trocas gasosas) da alface.

\section{AGRADECIMENTOS}

Ao PET-Agronomia da Universidade Federal do Ceará, ao Núcleo de Estudos em Olericultura do Nordeste (NEON) e ao CNPq.

\section{REFERÊNCIAS}

ASSOCIAÇÃO BRASILEIRA DO COMÉRCIO DE SEMENTES E MUDAS (ABCSEM). 20 Levantamento de dados socioeconômicos da cadeia produtiva de hortaliças no brasil. Holambra, 2014. Disponível em: <http://www.abcsem.com.br>. Acesso em Outubro de 2016.

ALENCAR, G. V.; MENDONÇA, E. S.; OLIVEIRA, T. S.; JUCKSCH, I.; CECON, P. R. Percepção ambiental e uso do solo por agricultores de sistemas orgânicos e convencionais na Chapada da Ibiapaba, Ceará. Revista Economia e Sociológica Rural, v. 51, n. 2, p. 217-236, 2013. Disponível em: <http://www.scielo.br/scielo.php?script=sci_arttext\&pid=S010320032013000200001\& Ing=en\&nrm=iso > doi:10.1590/S010320032013000200001.c

FILGUEIRA, F. A. R. Novo Manual de Olericultura: agrotecnologia moderna na produção e comercialização de hortaliças. 3 ed. Viçosa, MG: UFV, 621p. 2008.

HEREDIA ZÁRATE, N.; VIEIRA, M. C.; HELMICH, M.; HEID, D. M.; MANEGATI, T. Produção agroeconômica de três variedades de alface: cultivo com e sem amontoa. Revista Ciência Agronômica, v. 41, n. 4, p. 646-653, 2010. Disponível em:<http://www.scielo.br/scielo.php?script=sci_arttext\&pid=S1806-

66902010000400019>. doi: 10.1590/S1806-66902010000400019

KERBAUY, G. B. Fisiologia vegetal. 2. ed. Rio de Janeiro: Guanabara Koogan. 431p. 2012.

KHATOUNIAN, C. A. A reconstrução ecológica da agricultura. 1.ed. Botucatu: Agroecológica, 348p. 2001.

NODARI, R. O.; GUERRA, M. P. A agroecologia: estratégias de pesquisa e valores. Estudos avançados, v. 29, n. 83, p.183-207, 2015. Disponível em: http://www.scielo.br/scielo.php?script=sci_arttext\&pid=S0103-40142015000100183. doi: 10.1590/S0103-40142015000100010.

PENTEADO, S. R. Manual prático de agricultura orgânica: Fundamentos e técnicas. 2 ed. São Paulo: Via Orgânica. 232p. 2010.

SALA, F. C.; COSTA, C. P. Retrospectiva e tendência da alfacicultura brasileira. Horticultura Brasileira, v. 30, n. 2, p. 187-194, 2012. Disponível em: $<$ http://www.scielo.br/scielo.php?script=sci_arttext\&pid=S0102-

$05362012000200002 \&$ Ing=en\&nrm=iso>. doi: $10.1590 /$ S0102-05362012000200002. 
TAIZ, L.; ZEIGER, E. Fisiologia Vegetal. 5.ed. Porto Alegre, Artmed, p. 954. 2013.

THUN, M. O trabalho na terra e as constelações. Botucatu: Associação Brasileira de Agricultura Biodinâmica. 56p. 1986.

THUN, M. Calendário Astronômico-Agrícola 2015. Botucatu: Associação Brasileira de Agricultura Biodinâmica. 198p. 2015. 